COSTING:Journal of Economic, Business and Accounting

Volume 4 Nomor 2, Juni 2021

e-ISSN : 2597-5234

\title{
PENGARUH BAURAN PEMASARAN TERHADAP KEPUTUSAN PEMBELIAN KONSUMEN PRODUK KARTU PERDANA PASCABAYAR HALO PADA PT. TELKOMSEL GRAPARI MAKASSAR
}

\author{
EFFECT OF MARKETING ON CONSUMER PURCHASE DECISION ON \\ PRIVATE CARD PRODUCTS IN PT. TELKOMSEL GRAPARI MAKASSAR
}

\author{
Safrida $^{1}$, Musmulyadi ${ }^{2}$ \\ STIE Bajiminasa Makassar Indonesia ${ }^{1}$, IAIN Pare-Pare Indonesia ${ }^{2}$ \\ Syafrida168@gmail.com
}

\begin{abstract}
This research was conducted with the aim of: (1) examining and analyzing the effect of the product on consumer purchasing decisions for postpaid hello card products; (2) examining and analyzing the effect of price on consumer purchasing decisions for postpaid starter pack hello; (3) examining and analyzing the effect of promotion on consumer purchasing decisions for postpaid starter pack hello; (4) examining and analyzing the effect of place on consumer purchasing decisions for postpaid starter pack hello; (5) examining and analyzing the four factors that have the most dominant influence on consumer purchasing decisions for postpaid hello card products. This study uses primary data and secondary data. In this study, the sample used was 100 consumers. based on secondary data at the end of 2015 to December 2016. Data was collected through questionnaires and data tabulation was carried out. Methods of data analysis using multiple linear regression analysis and analysis of the coefficient of determination and descriptive analysis with the help of the Statistical Product and Service Solutions (SPSS) program. These results indicate that: (1) the product variable has a positive but insignificant effect on consumer decision making to buy postpaid starter pack hello: (2) the price variable has a positive and significant effect on the decision to buy a postpaid starter pack hello: (3) promotion variable has a significant effect on the decision to buy postpaid starter pack hello: (4) the place variable does not have a positive and significant effect on the decision to buy the postpaid starter card hello: (5) the most dominant variable influencing decision making is the price variable.
\end{abstract}

Keywords: Product, Price, Place, Promotion, and Purchase Decision

\begin{abstract}
ASBTRAK
Penelitian ini dilakukan dengan tujuan untuk : (1) menguji dan menganalisis pengaruh produk terhadap keputusan pembelian konsumen produk kartu pascabayar halo; (2) menguji dan menganalisis pengaruh harga terhadap keputusan pembelian konsumen produk kartu perdana pascabayar halo; (3) menguji dan menganalisis pengaruh promosi terhadap keputusan pembelian konsumen produk kartu perdana pascabayar halo; (4) menguji dan menganalisis pengaruh tempat terhadap keputusan pembelian konsumen produk kartu perdana pascabayar halo; (5) menguji dan menganalisis dari keempat faktor yang paling berpengaruh dominan terhadap keputusan pembelian konsumen produk kartu pascabayar halo. Penelitian ini menggunakan data primer dan data sekunder. Dalam penelitian ini sampel yang digunakan adalah 100 orang konsumen. berdasarkan data sekunder akhir tahun 2015 s.d desember 2016. Pengumpulan data
\end{abstract}


dilakukan melalui kuesioner dan dilakukan tabulasi data. Metode analisis data menggunakan analisis regresi linear berganda dan analisis koefisien determinasi dan analisis deskriptif dengan bantuan program Statistical Product and Service Solutions ( SPSS ). Hasil ini menunjukkan bahwa : (1) variabel produk mempunyai pengaruh positif tetapi tidak signifikan terhadap pengambilan keputusan konsumen membeli produk kartu perdana pascabayar halo: (2) variabel harga mempunyai pengaruh yang positif dan signifikan terhadap pengambilan keputusan membeli kartu perdana pascabayar halo : (3) variabel promosi berpengaruh signifikan terhadap pengambilan keputusan membeli kartu perdana pascabayar halo : (4) variabel tempat tidak mempunyai pengaruh yang positif dan signifikan terhadap pengambilan keputusan membeli kartu perdana pascabayar halo : (5) variabel yang paling dominan mempengaruhi pengambilan keputusan adalah variabel harga.

Kata Kunci : Produk, Harga, Tempat, Promosi, Keputusan Pembelian

\section{PENDAHULUAN}

Dewasa ini keanekaragaman aktivitas masyarakat dengan tidak mengenal waktu dan tempat, menyebabkan masyarakat membutuhkan suatu hubungan komunikasi yang baik dan handal serta dapat dilakukan dimana saja. Tingginya mobilitas masyarakat tersebut mutlak memerlukan suatu alat komunikasi yang memiliki kemampuan tinggi dalam mendukung berbagai aktivitas.

Telepon selular (ponsel) yang merupakan telepon bermobilitas tinggi tanpa kabel adalah jawaban dari kendala yang dihadapi masyarakat yang senantiasa membutuhkan suatu jaringan komunikasi bergerak yang handal, aman dan dapat digunakan kapan dan dimana saja komunikasi itu dibutuhkan (Masbahah, 2011).

Era telepon selular, khususnya Global System for Mobile Communications (GSM), memang baru marak dalam beberapa tahun belakangan ini. Kinerja sebuah ponsel sangat tergantung pada kecepatan mengatasi masalah pelayanan purna jual yang sangat diharapkan oleh pelanggan (Iqbal, 2013).

Seiring perkembangan pesat industri ini, minat investor pun semakin besar. Munculnya beberapa operator selular menimbulkan persaingan yang semakin ketat pada industri telekomunikasi selular ini, sehingga dari sisi penawaran, produk telekomunikasi selular semakin bertambah dan beraneka ragam. Oleh karena itu, masyarakat mempunyai banyak pilihan dan mereka semakin selektif dalam memilih dan memutuskan pada operator selular mana dan pada produk apa yang akan mereka gunakan.

Tabel 1 Perbandingan Jumlah Pelanggan Operator Selular di Indonesia (dalam ribuan)

\begin{tabular}{lcccc}
\hline Operator & $\begin{array}{c}\text { Jumlah } \\
\text { Pelanggan }\end{array}$ & $\begin{array}{c}\text { Pangsa } \\
\text { Pasar }\end{array}$ & $\begin{array}{c}\text { Jumlah } \\
\text { Pelanggan }\end{array}$ & $\begin{array}{c}\text { Pangsa } \\
\text { Pasar }\end{array}$ \\
\hline Selular & $\begin{array}{c}\text { akhir tahun } \\
\mathbf{2 0 1 5}\end{array}$ & $\begin{array}{c}\text { tahun } \\
\mathbf{2 0 1 5}\end{array}$ & $\begin{array}{c}\text { akhir tahun } \\
\mathbf{2 0 1 6}\end{array}$ & tahun 2016 \\
\hline Telkomsel & 24.270 & $47 \%$ & 34.900 & $51 \%$ \\
\hline Indosat & 14.500 & $28 \%$ & 14.700 & $24 \%$ \\
\hline $\begin{array}{l}\text { Excelcomin } \\
\text { do }\end{array}$ & 6.978 & $14 \%$ & 9.528 & $14 \%$ \\
\hline Smartfren & 4.062 & $8 \%$ & 3.900 & $6 \%$ \\
\hline Lain-lain & 1.625 & $3 \%$ & 3.202 & $5 \%$ \\
\hline Total & $\mathbf{5 1 . 4 3 5}$ & $\mathbf{1 0 0 \%}$ & $\mathbf{6 8 . 2 3 0}$ & $\mathbf{1 0 0 \%}$ \\
\hline
\end{tabular}

(Sumber : Data Sekunder ; 2016)

Laporan Tahunan 2016 PT. Telkomsel menunjukkan bahwa total jumlah pelanggan operator selular di Indonesia pada akhir tahun 2015 sebesar 51,4 juta pelanggan. Dari total 51,4 juta pelanggan tersebut, Telkomsel 
menduduki peringkat pertama dengan pangsa pasar sebesar $47 \%$, disusul dengan Indosat sebesar 28\%, kemudian berturut-turut Excelcomindo dengan pangsa pasar sebesar 14\%, Smartfren sebesar $8 \%$ dan sisanya sebesar 3\% adalah operator selular lainnya.

Sedemikian

pertumbuhan pemasaran jasa-jasa telekomunikasi, sehingga dirasakan adanya gejala persaingan yang semakin tajam antar perusahaan. Hal ini dapat dilihat dari berbagai produk yang ditawarkan oleh masing-masing perusahaan (Sitompul, 2020).

Menurut Kotler dan Amstrong (2008) ada dua (2) jalur identifikasi peluang pasar yaitu identifikasi terhadap produk yang sudah ada dan identifikasi terhadap produk baru . Dari kedua identifikasi tersebut maka ada empat bagian utama yang harus dilakukan oleh pemasar yaitu penetrasi pasar, perluasan pasar, pengembangan produk dan diverifikasi.

Kegiatan pemasaran umumnya memfokuskan diri pada produk, penetapan produk, kebijakan distribusi, dan cara promosi yang dalam hal ini dikenal sebagai bauran pemasaran. Setelah perusahaan memutuskan strategi pemasaran kompetitifnya secara keseluruhan, perusahaan harus mulai menyiapkan perencanaan bauran pemasaran yang rinci, yang selanjutnya dipahami sebagai bauran pemasaran (Saleh dan Miah 2019).

Pengertian bauran pemasaran Menurut Kotler \& Amstrong (2008) adalah seperangkat alat pemasaran taktis dan terkontrol yang dipadukan oleh perusahaan untuk menghasilkan respon yang diinginkan pasar sasaran. Kombinasi dari strategi produk, harga, promosi, dan distribusi dalam mencapai tujuan pemasaran dinamakan "Marketing Mix" yang dikenal dengan strategi 4P (Product, Price, Place,
Promotion) dalam pemasaran merupakan alat bagi produsen untuk mempengaruhi konsumen.

\section{METODE PENELITIAN}

\section{Populasi dan Sampel}

Adapun yang menjadi populasi dalam penelitian ini adalah pelanggan aktif kartu pascabayar Halo Telkomsel sebanyak 873.431 orang. Untuk menentukan minimal sampel yang dibutuhkan jika ukuran populasi diketahui, digunakan rumus Slovin (Husain Umar, 2003:108) sebagai berikut:

$$
\begin{aligned}
& \mathbf{n}= \mathbf{N} /\left(\mathbf{1}+\mathbf{N e}^{\mathbf{2}}\right) \\
& \mathrm{n}= \text { Ukuran sampel } \\
& \mathrm{N}= \text { Ukuran populasi } \\
& \mathrm{e}=\text { Kelonggaran ketidaktelitian } \\
& \text { karena kesalahan pengambilan } \\
& \text { sampel yang dapat ditolerir } \\
& \mathrm{n}= 873.431 /\left(1+873.431 \times 0.1^{2}\right) \\
& \mathrm{n}= 873.431 /\left(873.431^{`}+873.531\right) \\
& \mathrm{n}= 873.431 /(8735,31) \\
& \mathrm{n}= 99,9885, \text { dibulatkan menjadi } 100 \\
& \text { orang. }
\end{aligned}
$$

Dalam penelitian ini, jumlah populasi pelanggan kartu pascabayar Halo sebesar 873.431 orang, dengan persentase kelonggaran adalah $10 \%$, maka melalui perhitungan diatas, ukuran sampel yang diperoleh akan menjadi 100 orang.

\section{Metode dan Analisis Data Uji Regresi Linear Berganda}

Uji regresi linear berganda dilakukan untuk mengukur seberapa besar pengaruh dari variabel produk, harga, tempat, dan prmosi terhadap pengambilan keputusan. Agar diperoleh hasil perhitungan koefisien regresi yang tepat dalam pengolahan data digunakan program statistik yaitu SPSS. Hasil uji regresi linier 
berganda dapat dilihat pada tabel 14 sebagai berikut :

Tabel 2 Hasil Analisa Regresi Berganda

\begin{tabular}{|c|c|c|c|c|c|c|}
\hline \multirow{2}{*}{\multicolumn{2}{|c|}{ Model }} & \multicolumn{2}{|c|}{$\begin{array}{c}\text { Unstandardized } \\
\text { Coefficients }\end{array}$} & \multirow{2}{*}{$\begin{array}{c}\begin{array}{c}\text { Standardized } \\
\text { Coefficients }\end{array} \\
\text { Beta }\end{array}$} & \multirow[t]{2}{*}{$\mathrm{t}$} & \multirow[t]{2}{*}{ Sig. } \\
\hline & & B & Std. Error & & & \\
\hline \multirow[t]{5}{*}{1} & (Constant) & 4.412 & 1.872 & & 2.357 & .020 \\
\hline & Produk & .216 & .117 & .173 & 1.843 & .069 \\
\hline & Harga & .356 & .122 & .284 & 2.912 & .004 \\
\hline & Tempat & .129 & .121 & .092 & 1.070 & .287 \\
\hline & Promosi & .274 & .105 & .250 & 2.606 & .011 \\
\hline
\end{tabular}

Dari nilai-nilai koefisien di atas, dapat disusun persamaan regresi berganda sebai berikut:

$\mathrm{Y}=4,412+0,216 \mathrm{X} 1+0,356 \mathrm{X} 2+$ $0,129 \times 3+0,274 \times 4$

Dimana:

1. $\mathrm{B}_{0}=4,412$ adalah bilangan konstanta yang berarti apabila variabel produk, harga, tempat dan promosi sama dengan nol, maka besarnya variabel terikat yaitu pengambilan keputusan adalah 4,412 .

2. $\mathrm{B}_{1}=0,216 \mathrm{X} 1$ adalah besarnya koefisien regresi variabel produk yang berarti setiap peningkatan variabel produk sebesar 1 poin maka pengambilan keputusan membeli kartu perdana pascabayar Halo di PT. Telkomsel akan meningkat sebesar 0,216 dengan asumsi variabel bebas lainnya konstan.

3. $\mathrm{B}_{2}=0,356 \mathrm{X} 2$ adalah besarnya koefisien regresi variabel harga yang berarti setiap peningkatan variabel harga sebesar 1 poin maka pengambilan keputusan membeli kartu perdana pascabayar Halo di PT. Telkomsel akan meningkat sebesar 0,356 dengan asumsi variabel bebas lainnya konstan.

4. $\mathrm{B}_{3}=0,129 \times 3$ adalah besarnya koefisien regresi variabel tempat yang berarti setiap peningkatan variabel tempat sebesar 1 poin maka pengambilan keputusan membeli kartu perdana pascabayar Halo di PT. Telkomsel akan meningkat sebesar 0,129 dengan asumsi variabel bebas konstan.

5. $\mathrm{B}_{4}=0,274 \mathrm{X} 4$ adalah besarnya koefisien regresi variabel promosi yang berarti setiap peningkatan variabel promosi sebesar 1 poin pengambilan keputusan membeli kartu perdana pascabayar Halo di PT. Telkomsel akan meningkat sebesar 0,274 dengan asumsi variabel bebas lainnya konstan.

Hasil regresi berganda menunjukkan bahwa variabel produk, harga, tempat dan promosi berpengaruh positif terhadap variabel pengambilan keputusan membeli kartu perdana pasca bayar Halo di PT. Telkomsel. Selain itu dari hasil tersebut dapat dilihat bahwa variabel bebas yang dominan adalah variabel harga sebesar 0,356.

\section{Pengujian Hipotesis Uji F (Simultan)}

Uji simultan atau uji $\mathrm{F}$ merupakan uji secara bersama-sama variabel bebas terhadap variabel terikat atau untuk menguji signifikan pengaruh variabel produk, harga, tempat dan promosi secara bersama-sama terhadap variabel pengambilan keputusan membeli kartu perdana pascabayar Halo di PT. Telkomsel. Uji $\mathrm{F}$ dilakukan dengan membandingkan Fhitung dengan Ftabel. 
Tabel 3. Hasil Uji F

\begin{tabular}{lcrrrrr}
\hline Model & $\begin{array}{c}\text { Sum of } \\
\text { Squares }\end{array}$ & df & $\begin{array}{c}\text { Mean } \\
\text { Square }\end{array}$ & F & Sig. \\
\hline 1 Regression & 65.494 & 4 & 16.374 & 11.476 & $.000^{\mathrm{a}}$ \\
\hline Residual & 135.546 & 95 & 1.427 & & \\
\hline Total & 201.040 & 99 & & & \\
\hline
\end{tabular}

Berdasarkan hasil regresi berganda dari tabel 3 menunjukkan Fhitung sebesar 11,476, sedangkan hasil Ftabel pada tabel tempat pada tingkat kesalahan $5 \%$ adalah sebesar 2,47. Hal ini berarti Fhitung $>$ Ftabel $(11,476>2,47)$. Perhitungan tersebut menunjukkan bahwa variabel produk, harga, tempat dan promosi secara bersama-sama mempunyai pengaruh yang positif dan signifikan terhadap variabel pengambilan keputusan membeli kartu perdana pascabayar Halo di PT. Telkomsel. Maka penulis menyimpulkan hipotesis penelitian ini yang menyatakan variabel produk, harga, tempat dan promosi secara bersama-sama berpengaruh terhadap pengambilan keputusan membeli kartu perdana pascabayar Halo di PT. Telkomsel.

\section{Uji t (Parsial)}

Pengujian ini untuk melihat sejauh mana pengaruh masing-masing variabel bebas terhadap variabel terikat berdasarkan hasil regresi. $\mathrm{Uji} t$ dilakukan dengan membandingkan nilai $\mathrm{t}$ hitung dengan $\mathrm{t}$ tabel dengan tingkat kesalahan $5 \%$ yakni 1,985. Apabila t hitung $>\mathrm{t}$ tabel maka dapat disimpulkan variabel tersebut mempunyai pengaruh yang signifikan.

1. Variabel Produk. Nilai thitung untuk variabel produk sebesar 1,843 . Sementara itu nilai pada tabel tempat $5 \%$ sebesar 1,843, maka thitung $(1,843)<$ ttabel $(1,985)$. Hal ini berarti variabel produk tidak mempunyai pengaruh yang signifikan terhadap pengambilan keputusan membeli kartu perdana pascabayar Halo di PT. Telkomsel.

2. Variabel Harga. Nilai thitung untuk variabel ini sebesar 2,912. Sementara itu nilai pada tabel tempat 5\% sebesar 1,985. Maka thitung $(2,912)>$ tabel $(1,985)$. Hal ini berarti variabel harga mempunyai pengaruh yang positif dan signifikan terhadap pengambilan keputusan membeli kartu perdana pascabayar Halo di PT. Telkomsel.

3. Variabel Tempat. Nilai thitung untuk variabel ini sebesar 1,070. Sementara itu nilai pada tabel tempat $5 \%$ sebesar 1,985. Maka thitung $(1,070<$ tabel $(1,985)$. Hal ini berarti variabel tempat tidak mempunyai pengaruh yang positif dan signifikan terhadap pengambilan keputusan membeli kartu perdana pascabayar Halo di PT. Telkomsel.

4. Variabel Promosi. Nilai thitung untuk variabel ini sebesar 2,606. Sementara itu nilai pada tabel tempat $5 \%$ sebesar 1,985. Maka thitung $(2,606)>$ tabel $(1,985)$. Hal ini berarti variabel promosi mempunyai pengaruh yang positif dan signifikan terhadap pengambilan keputusan membeli kartu perdana pascabayar Halo di PT. Telkomsel.

Berdasarkan hasil uji $\mathrm{t}$ di atas maka dapat disimpulkan bahwa variabel produk dan tempat tidak memiliki pengaruh signifikan terhadap pengambilan keputusan membeli kartu perdana pascabayar Halo di PT. Telkomsel. Sedangkan variabel harga dan promosi memiliki pengaruh yang positif dan signifikan terhadap pengambilan keputusan membeli kartu perdana pascabayar Halo di PT. Telkomsel. Variabel yang paling 
dominan mempengaruhi pengambilan keputusan adalah variabel harga dengan nilai $t$ hitung yang paling besar (2,912), dengan signifikan sebesar 0,004 .

\section{PENUTUP}

\section{Kesimpulan}

Penelitian ini bertujuan untuk mengetahui pengaruh bauran pemasaran dengan variabel produk, harga, tempat dan promosi terhadap keputusan pembelian konsumen produk kartu Halo di PT. TELKOMSEL (grapari) Makassar. Dan untuk mengetahui pengaruh dari keempat variabel independent tersebut. Dari rumusan masalah penelitian yang diajukan, maka analisis data yang telah dilakukan dan pembahasan yang telah dikemukakan pada bab sebelumnya, dapat ditarik beberapa kesimpulan berdasarkan dari Hipotesis penelitian ini yaitu sebagai berikut :

1. Variabel Produk. Berdasarkan hasil analisis regresi linear berganda dapat ditarik kesimpulan bahwa variabel produk tidak memiliki pengaruh yang signifikan terhadap keputusan pembelian konsumen, koefisien pengaruh tersebut menunjukkan pengaruh positif tetapi tidak signifikan yang artinya bahwa semakin tinggi persepsi pelanggan atau pelanggan produk kartu perdana pascabayar halo di PT. Telkomsel Makassar terhadap kualitas produk tidak serta merta memiliki daya tarik untuk membeli kartu perdana. Hal ini menunjukkan bahwa kualitas kartu perdana pascabayar halo di PT. Telkomsel Makassar tidak serta merta menarik pelanggan untuk membeli, disinyalir karena produk ini memiliki segmentasi kelas menengah keatas, selain itu pembeli memiliki pertimbangan lain untuk memilih keputusan membeli kartu perdana pascabayar Halo di PT.Telkomsel Makassar.

2. Variabel Harga. Berdasarkan hasil analisis regresi linear berganda menunjukkan adanya pengaruh positif dan signifikan yang dapat diartikan bahwa semakin terdapat kesesuaian antara harga dengan kemampuan pelanggan dalam membeli produk kartu perdana pascabayar halo, maka pelanggan semakin tertarik untuk membeli produk tersebut. Hal ini juga menunjukkan bahwa semakin baik dalam menentukan harga produk kartu perdana pascabayar halo yang di berikan kepada pelanggan, maka pelanggan semakin merasa puas dalam memilih keputusan untuk membeli produk kartu perdana pascabayar Halo di PT.Telkomsel Makassar.

3. Variabel Tempat. Berdasarkan hasil analisis linear berganda menunjukkan adanya pengaruh tetapi tidak signifikan, yang dapat diartikan bahwa tidak terdapat kesesuaian antara keterjangkauan tempat lokasi pembelian dengan kemampuan pelanggan dalam membeli kartu perdana sehingga pelanggan tidak memiliki ketertarikan untuk membeli produk kartu perdana pascabayar halo di PT. Telkomsel Makassar. Hal ini juga menunjukkan bahwa semakin baik dalam memilih lokasi tempat produk tidak menjadikan pelanggan puas dalam memilih keputusan untuk membeli produk kartu perdana pascabayar Halo di PT. Telkomsel Makassar.

4. Variabel Promosi. Berdasarkan hasil analisis linear berganda menunjukkan adanya pengaruh positif dan signifikan, yang dapat diartikan bahwa semakin terdapat 
kesesuaian informasi yang disampaikan melalui promosi dengan keberadaan produk, maka pelanggan semakin memiliki ketertarikan untuk membeli produk kartu perdana pascabayar Halo di PT. Telkomsel Makassar. Hal ini juga menunjukkan bahwa semakin baik dalam mengelola promosi produk-produk kartu perdana pascabayar Halo di PT. Telkomsel Makassar yang ditunjukkan kepada pelanggan atau calon pelanggan, maka masyarakat semakin merasa tertarik dalam memilih keputusan untuk membeli produk kartu perdana pascabayar Halo di PT. Telkomsel Makassar.

5. Variabel Harga. Variabel harga dan promosi memiliki pengaruh yang positif dan signifikan terhadap pengambilan keputusan membeli kartu perdana pascabayar Halo di PT. Telkomsel. Variabel yang paling dominan mempengaruhi pengambilan keputusan adalah variabel harga.

Berdasarkan hasil uji t di atas maka dapat disimpulkan bahwa variabel produk dan tempat tidak memiliki pengaruh signifikan terhadap pengambilan keputusan membeli kartu perdana pascabayar Halo di PT. Telkomsel.

\section{Saran}

Adapun saran-saran dari Penulis sesuai dengan Pengetahuan Penulis, maka penelitian ini memberikan beberapa saran sebagai berikut :

1. Sebaiknya Perusahaan PT. TELKOMSEL (grapari) Makassar Mempertahankan produk yang sudah ada, serta menambah produk sesuai dengan kebutuhan dan keinginan masyarakat karena diliat dari semakin bertambahnya jaringan operator yang semakin berkembang saat ini maka akan semakin ketat pula persaingan yang akan dihadapi kedepannya.

2. Sebaiknya PT. TELKOMSEL (grapari ) Makassar agar terus mempertahankan dan memelihara kesesuaian Harga yang sudah dikenal oleh masyarakat.

3. Bagi Management PT. TELKOMSEL (grapari) Makassar agar lebih ditingkatkan lagi Faktorfaktor yang mempengaruhi keputusan konsumen.

4. Bagi penulis selanjutnya dapat diakukan penelitian dengan variabel bebas lain, sehingga variabel yang mempengaruhi keputusan konsumen dapat teridentifikasi lebih banyak lagi.

\section{DAFTAR PUSTAKA}

Iqbal, M. (2013). Pelayanan yang memuaskan. Elex Media Komputindo.

Kotler, Philip, Armstrong, Gary. (2008). Prinsip-Prinsip Pemasaran, Jilid1 (Edisi 12). Jakarta: Erlangga

Masbahah, N. (2011). Hand Phone Sebagai Gaya Hidup: Studi Kasus Dikalangan Mahasiswa Fakultas Ekonomi Dan Bisnis Universitas Airlangga Surabaya (Doctoral Dissertation, UIN Sunan Ampel Surabaya).

Saleh, H. M. Y., \& Miah Said, S. E. (2019). Konsep dan Strategi Pemasaran: Marketing Concepts and Strategies, 1(1). SAH MEDIA. 
Sitompul, S. S. (2020). Pengaruh Produk, Harga, Tempat, Promosi, Bukti Fisik, Orang, Proses terhadap Keputusan Pembelian Pada PT. Central Bearindo International Pekanbaru. Management Studies and Entrepreneurship Journal (MSEJ), 1(2), 178-187. 